\title{
Airbnb and cultural capitalism: enclosure and control within the sharing economy
}

\author{
Michael O' Regan and Jaeyeon Choe
}

\section{ABSTRACT}

Collectively termed the "Sharing Economy", collaborative platforms are said to be challenging and redesigning traditional business models and ridding the tourism industry of monopolies and resource inefficiencies as they efficiently allocate assets and human resources. This paper explores the global "disruptive" brand Airbnb by utilizing the concept of cultural capitalism to ask questions as to how disruptive and innovative this platform is. We conclude that research about Airbnb and the sharing economy needs to overcome ahistorical, static, and narrow perspectives to integrate critical theories using diverse intellectual approaches to more fully explore platform's that seek enclosure and control so as to allow market capitalism to function more expediently.

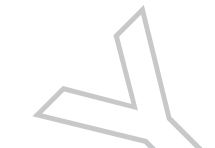

ARTICLE HISTORY

Received 5 May 2016

Accepted 14 January 2017

\section{KEYWORDS}

Sharing economy; cultural

capitalism; Airbnb;

reputational capital;

commodification

\section{Introduction}

Across the globe, there has been a rapid explosion in sharing, bartering, lending, trading, renting, and swapping because of new social technologies as well as economic, social, and environmental imperatives. A new consumptive model that unlocks assets and spare capacity is being promoted as moving tourists and even societies away from hyper-consumption. It is said to offer health, emotional and spiritual benefits, as well as boosting living standards across the globe (Chase, 2015; Howard, 2015; Krakovsky, 2015; Kramer, 2015). This model is said to foster sustainable marketplaces (Phipps et al., 2013) by optimizing the "environmental, social, and economic consequences of consumption in order to meet the needs of both current and future generations" (Luchs et al., 2011, p. 2). It is also said to drive productivity, entrepreneurship, intercultural understanding, and innovation (Botsman \& Rogers, 2011) and create new kinds of relationships that changes how we consume, socialize, move, and dwell. Collectively termed the "Sharing Economy" (SE), it is described by Botsman (2015, n.p.) as an "an economic system based on sharing underused assets or services, for free or for a fee, directly from individuals".

The SE sector has attracted entrepreneurs, the public sector, tourism authorities, venture capitalists, and start-up corporations to a sector with an estimated global worth of US $\$ 335$ bn by 2025 (PwC, 2014). It has also attracted those with consistent and specific motivations to offer, share or lease products, skills and capital deemed valuable to tourist desires and needs. A consumer survey reported in 2015 that nearly half of all Americans (46\%) participated in one or more aspects of the sharing economy 
(King, 2015), while a 2016 Pew Research Center poll put the figure at 72\% (Smith, 2016). While consumers are familiar with SE brands, they are not familiar with the SE concept itself, with the poll also finding that $73 \%$ of Americans are not familiar with the term "sharing economy" (Smith, 2016).

Different strands of academic scholarship on the SE have originated across different disciplines such as management and business studies, economics and sociology. Within tourism studies, paradigms from which the SE has been viewed include lifestyle and social movement fields, consumption models and innovation theory (Cheng, 2016; Guttentag, 2016). Within these studies, however, a theoretical framework to understand the SE phenomenon is lacking. This paper informs that conceptual problem by applying the concept of cultural capitalism to the global accommodation supplier Airbnb. By 10 applying capitalist theory to Airbnb, this paper reveals how critical questions are not being asked about the platform. We utilize Airbnb as an example, as it's the primary SE platform said to be disrupting and reshaping the accommodation sector, and the tourism industry as a whole. Through the prism of cultural capitalism, we explore Airbnb and control and Airbnb and reputational capital so as to identify the impacts of Airbnb on cultural, economic, political, and consumer worlds.

\section{Literature review}

Airbnb's novel supply chain and operations model is said to be a libertarian revolt against the oppressive social organizations characterized by entrenched outdated business models and big government (Moazed \& Johnson, 2016). Founded in 2008, Airbnb has embraced the egalitarian and anti-hierarchical rhetoric of the counterculture to match hosts with guests who rent out their homes and rooms for a fee. An accommodation provider that owns no property, it offers more than 2 million listings in more than 190 countries worldwide. With approximately US\$7.5 billion in gross bookings in 2015 (Quinby, 2016), Airbnb has become one of the world's largest online travel companies with more than 40 million people renting accommodation via the platform between 2008 and 2015.

Airbnb is a for-profit business with a vertical, linear structure that uses user interfaces, software, and algorithms on its platform to control what is shared, with whom, and for what purposes. It rides on the network effect of the more people who join Airbnb, the more useful it is and the more valuable it becomes as a vehicle to generate revenue. When Airbnb wants to add more rooms, it just needs someone to create a new listing. Airbnb has grown to a global brand worth US\$30 billion (2016) by avoiding what they see as outdated regulations covering the accommodation sector. Airbnb argues it

30 should be exempt from existing regulations because the services are ordered over the Web and therefore not subject to "local" regulation such as existing local housing ordinances or laws pertaining to hotels in certain locations (Sperling, 2015). It has increasingly sought to fight any regulation or ordinance that impacts its growth strategy. After San Francisco and Santa Monica (California) introduced regulations to curb Airbnb and home sharing in 2016, Airbnb sued by claiming they are not accountable for

35 (illegal) rental listings or for the content that is published by their hosts as well as online transactions and fees due to protections enabled by the Communications Decency Act of 1996.

As a community-driven hospitality company, tourism is central to Airbnb, with Airbnb claiming to diversify the accommodation base of destinations around the globe as well as spreading tourists to neighbourhoods and communities beyond traditional tourist destinations. Its 2016 marketing cam40 paign "Live There" was designed in response to "the growing dissatisfaction and disappointment with standardized tourist offerings that have become the hallmark of modern tourism" (Airbnb, 2016).

\section{Methodology}

This paper uses the concept of "Cultural capitalism" developed and/or used by Rifkin (2000), Žižek (2006, 2009a) and Holloway (2010) to address the Airbnb phenomenon. They believe a new stage of commodification that does not change the basic rules of capitalism is emerging. We no longer buy products we want to own, but seek life experiences to render life meaningful. In a new age of access where intangible assets are in ascendancy, businesses are increasingly mining new assets and resources 
(Rifkin, 2000) and turning them into commodified life experiences (experiences of sex, eating, communication, cultural consumption, participation in a lifestyle) and brand communities.

As "everything is accessed" (Rifkin, 2000, p. 6), experiences are increasingly offered for low transactional cost in order to seduce tourists into buying the experiential commodities that offer communicate cultural meaning. From homestays, cooking, and craft classes, experiential tourism is being immersed as you create meaning through direct experience (Campos, do Valle, Mendes, \& Scott, 2015; Howell, Pchelin, \& Iyer, 2012). Access to private homes and luxury cars serve merely as props, while access to local guides, home-cooked meals and paid- for romantic dates with locals highlight how the intimate, social, and cultural spheres are being pulled into the commercial sphere through
vast supplier-user networks controlled primarily by private companies. Žižek (2009a, p. 52) argues that one becomes server or client, supplier or user as "social relationality in its very fluidity is directly the object of marketing and exchange" (Žižek, 2009a, p. 139).

Most what we label the SE merely expands the capitalist economy by way of capital accumulation in the face of a global, structural crisis (Holloway, 2010). Just as capitalism surged on the dot.com boom as corporations unlocked people's homes using subprime refinancing (Harvey, 1989), the SE mines individual assets and resources. These platforms are raiding, cracking open, exploiting, and releasing surplus value by using resources from private and public sources and repackaging them as cultural commodities and entertainment for the short-term benefit of stockholders, entrepreneurs, and venture capitalists, as well as the ultimate tourist consumer who leases them to tell stories, release emotions, create atmospheres, and provoke intense feelings (Ullrich, 2012).

SE platforms have flourished as they seek to persuade people to leverage physical, network, mobility, economic, cultural, human, social assets, and other resources so as to capitalize on their liquid and economic value by renting (sharing, leasing) them out to those that demand them. They connect individuals to information, other people, objects, ideas, lifestyles, capital, and physical things such as cars, apartments, tools, relationships, time, bodies, and friendship in more efficient ways. Blurring the lines between personal-commercial and private-public, anyone can use their assets and resources such as cars (to lease), spaces (a spare room), skills (food preparation, tour guiding, driving) and other goods, products, services, and utilities. Assets and resources with cultural dimensions have become particularly valuable and have become central to thousands of SE platforms that rely on technology to offer new dimensions to a service industry such as tourism. Platforms linked to the tourism industry have been at the forefront at seeking to unlock "idling capacity" and market them by emphasizing experiences, sharing, and community.

Airbnb is lauded as a disruptive innovator which provides access to social and cultural experiences to tourists on a budget by unlocking latent market demand and offering growth potential in an otherwise competitive and saturated marketplace (Stephany, 2015). It has been described as a means to disrupt the "out-dated" consumption and "anti-innovation" business models propagated by entrenched and monopolistic elements (Botsman \& Rogers, 2011) within the accommodation sector. While house owners act on economic-oriented motivations on the supply side (Hamari \& Ukkonen, 2013), tourists act on cost-savings and because Airbnb conveys an emotional, cognitive, and cultural attraction (Tussyadiah \& Pesonen, 2016). By applying the concept of cultural capitalism to Airbnb, we explore a world where money no longer buys (and sells) objects to attain cultural or emotional experiences, but a world where one directly buys (and sells) experiences.

\section{Discussion}

Airbnb promotes itself as a platform for those who have financially over-extended themselves in a tur-

bulent world economy. At a time of joblessness and high debt levels, as well as poverty in many tourist destinations, hosts are encouraged to extract value or productivity from their assets to offset rent or mortgages, and make life/austerity/depth bearable (Ahmed, 2014). However, Airbnb exercises control over the conditions and terms by which hosts secure access to the Airbnb marketplace. While lowering start-up friction costs (in the absence of paperwork), there are few protections like health coverage, 
insurance against injuries, paid vacations, pensions, maximum working hours, a stable income, job security, and other safeguards for those hosting via Airbnb and those working in the broader Airbnb ecosystem. From check-in and concierge services (e.g. Guesthop), cleaning (e.g. Proprly) to total property management (e.g. Happy Host, Airsorted.), Airbnb has facilitated an ecosystem without taxes, hourly ceilings, anti-discrimination laws, unions, health and safety regulations and minimum wages. Evidence suggests that the shift to on-demand labour may increase economic vulnerability (Katz \& Krueger, 2016) for those who work in the Airbnb ecosystem, given hosts may not abide by established accommodation sector initiatives such as paying unionized cleaners and supporting living wages.

Furthermore, these "micro-entrepreneurs" have, through little fault of their own, undermined

10 hard-fought protections and regulatory frameworks for those working in the accommodation sector. While giving the illusion that all that people need is a house to become a micro-entrepreneur, Airbnb makes the rules by which they must play. From the opaque service fee levels it adds to each transaction (e.g. 6-15\% fee) to the demands that hosts offer dependability, accuracy, authenticity, and a degree of emotional labour (Hochschild, 2003), Airbnb has gained control by way of a superior-subordi-

15 nate relationship. From sellers' fear of algorithms (how they appear in customers' search results) and hidden aspects of algorithms making (or ruining) reputations to Airbnb videos, hosting toolkits and mentors training hosts how to provide hospitality, micro-entrepreneurs rely on Airbnb for income and direction. From generating leads, marketing their properties, and taking payment, Airbnb's terms and conditions supersede individual preferences. Airbnb can delist hosts with no explanation (Lynam,

20 2016) and push for instant bookings, while the host prices that emerge on Airbnb are now largely the result of the Aerosolve pricing system created to simulate market mechanisms. As it predicts the optimal price for a rental based on its location, time of year, and a variety of other attributes, it blurs the line between Airbnb as a marketplace and as a more controlling actor.

\section{Airbnb and reputational capital}

Airbnb is dependent on confirming identity, so as to create trust between strangers and enabling trust to be conveyed by way of a bidirectional rating and reputational systems, background checks, and frictionless payment systems. By using various verification systems such as giving access to one's social graph on Facebook, creating personal profiles, peer reviews ratings, and official verifications, one is supposed to build reputation capital on Airbnb over time. Reputation capital reflects the market's beliefs about the likelihood that the host and guest will honour their guarantees (Ikkala \& Lampinen, 2014). Market-based reputation is often about control, manipulation, and discipline rather than transparency and accountability. A damaged reputation even when playing the role of a dutiful and dependent host is faced with the movement of financial capital away from her/him, while a person with excellent reputational capital collected from guest reviews will attract capital. Debord (1998, p. 18) argues that 35 reputations have become "malleable and alterable at will by those who control all information" and argues that you cannot believe anything about anyone that you have not directly learned for yourself.

Airbnb ratings have been found to be unreliable and skewed, which means ratings have no correlation with quality (Zervas, Proserpio, \& Byers, 2015). As Airbnb eliminates the possibility that buyers and sellers ever come into contact without some trust mechanism, relationships become dispensable as they are commoditized as part of the new enclosures of capital. Given Airbnb's terms of use note that it has "no control over the conduct" of hosts or guests, it is accused of facilitating discrimination. Airbnb hosts in various parts of the world allegedly have denied service to passengers with wheelchairs, minorities, and guide dog owners. A study by Wang, Xi, and Gilheany (2015) reveals the prevalence of racial discrimination among hosts in California, while Edelman, Luca, and Svirsky (2016) concluded that Airbnb facilitates discrimination based on a host's race, gender, age, or other characteristics. There is also no reputation mechanism to assist either hosts or tourists denied the use of Airbnb because of discrimination or access to protections that may normally cover accommodation provision and use.

While Airbnb introduced new anti-discrimination guidelines in 2016, there is no backstop to hosts' discriminating, or Airbnb facilitating the threat of violence, racism, sexism, and homophobia. Given 
terms and conditions of use require that people agree to waive their right to sue, join in class-action lawsuits or class-action arbitration; bodies that are coloured, disabled, queer, sick, and obese may be categorized as "out of place" by some hosts. Arias-Sans and Quaglieri Domínguez (2016) argue that hosts and guests share a similar approach around a "cosmopolitan sense of local" which might exclude a large proportion of "out-of-place" tourists and local residents. Airbnb instead has sought to control any measures that threaten the extractive nature of the platform by appealing to their consumerssellers to push regulators to loosen restrictions and regulatory protections. Hosts are not only tourist infrastructure, but also corporate activists.

Airbnb has embedded tools and incentives on its site to mobilize hosts in support of less restrictive 10 regulations, and has repeatedly asked its users to write to politicians, attend rallies, become involved volunteers and drive support for Airbnb within their own communities. Airbnb introduced a network of home-sharing guilds in cities across the North America in 2016 to act for the corporation, and become a formidable voting constituency as well offering training, tools, and support to these guilds to influence leading elected officials and organizations. This may help to ensure that Airbnb sees off

15 future policies or laws that act against its interests. Contemporary capitalist modernizers, like Airbnb seek to "diversify, devolve power, and try to mobilise local creativity and self-organisation" (Žižek, 2012, p. 165), without retaining any of the risks and responsibilities (Dredge \& Gyimóthy, 2015). Its promotion as a community-driven platform masks the authoritarian-style social control that pits its users against socio-democratic consensus in communities with the pretense of setting them free from big government, over-regulation, and constraints on their freedom.

Enclosure and control measures have provided space for Airbnb to commodity more resources in a process of "making things exchangeable on markets either actually and/or discursively by framing things as if they were exchangeable" (Sevignani, 2013, p. 733). From planning to turn host's homes into restaurants, to "hand-crafted" package holidays and listings especially for business travellers and a programme that pays hosts to recommend restaurants and offer tours (Airbnb, 2016); Airbnb is not only seeking to corner the whole travel experience, but the "lifetime value" (Rifkin, 2000) of each consumer tourist and those who supply them with experiences. Airbnb will soon be delivering ondemand experiences to tourists anywhere with domains once seen as private and partitioned become commoditized as part of a project that will see hosts offering themselves, their lives and communities offered up as experiential offerings.

\section{Implications}

Airbnb incorporates the language of the underdog, by using the theoretic of sharing. It argues it helps those with a spare bed to rent in order to make ends meet and those who could not travel because of the exclusionary and expensive traditional accommodation sector. While it argues it is taking on monopolistic tendencies and resisting existing socio-economic relations built on the conventional economy, Airbnb has been created through venture-capital-backing and transactional forms of collaboration. The utopian spin and frontend of such a service-oriented platform promotes socio-ideological motifs (care for the environment, social responsibility, communal life, human rights environmental protection, economic growth) and global geographical imaginaries (collaboration, social equity, solidarity, community, equality, trust, mobility justice, reciprocity, altruism, autonomy, intimacy, and authenticity) to legitimize their business model. Žižek (2011, p. 236) argues that cultural capitalism promotes solutions as "containing or providing the remedy against the consumerist excess", such as doing one's social and ecological duty. Tourists are evoked to buy into redemption by being a consumerist by Airbnb as it evokes a rebellious and anti-establishment spirit. An Airbnb transaction can stand for symbolic acts of personal commitment to the causes the tourists might invoke such as authenticity, solidarity, and community (Rifkin, 2000).

By selling varying slogans and ideas, such as helping the environment, and restoring a sense of community, endeavours on Airbnb become capitalism with a human face (Žižek, 2009b). Its 2015 "Never a Stranger" campaign sought to position it itself as a sustainable, anti-consumerism, culturally 
immersive, and transformative travel experience by showing a highly idealized version of the hostguest relationship. A 2016 "Don't Go There. Live There" campaign spot mocked tourist behaviour and set it against the "authentic" activities and experiences enabled by hosts. Such campaigns offer sentimentality, ethical interaction, and care for humanity, and promise us we can all feel good about using the platform and using the assets and resources of local hosts. While packaging their market communication along the rhetoric of morality and eco-ethics, they do not address or promote moral or ethical decision-making.

While nothing is wrong with collaboration, sharing, making money, or indeed technology, Airbnb works as a more efficient means to satisfy every tourist's wants and desires. While it may, through unintended effects, create some positive social, economic, and environmental benefits, it will not end the financial crisis, loneliness, climate change, peak oil, inequality, resource scarcity, loss of biodiversity and ecosystem resilience and unemployment. It will not contribute, to any great degree, to a more sustainable world, or more sustainable tourism marketplaces. Airbnb will not create secure and stable jobs, generate greater trust amongst hosts and guests, and make us greener or more ethical tourists and make up for inequality.

While Fiske (1992) argues that individuals can live simultaneously in a world where social norms prevail, and where market norms make the rules, trouble can ensue when social and market norms collide (Zelizer, 2005). As lines between public and private, community and the market, production and consumption, voluntary activity and precarious exploitation, commercial and intimate life, market and non-market, economic value and personal life become more permeable and harder to discern, the lines between Airbnb fact and fiction become blurred. While city reports authored by Airbnb detail benefits such as income creation and micro-entrepreneurship, other non-profit studies from the same cities point to the degradation of labour, socio-spatial inequalities and intimacy and distributional conflicts. Given that Airbnb is designed to nurture the needs of those who can afford access to paid hosts on the platform, there is a potential breakdown of reciprocity, intimacy, sympathy, understanding, and trust between those who perform services and those who pay for them.

While receiving everything, one desires that a commoditized "instant booking" transaction on Airbnb can be liberating for tourists, but it can also be dehumanizing for hosts as Airbnb conceal any monetizing of interaction and intimacy through frictionless booking and payment systems. As Airbnb move into vacation rentals, home-cooked meals and trip planning, our understanding of tourism as a composite commons is changed in both striking and subtle ways. From demonstrations in Barcelona, where Airbnb is accused of pushing out locals in the old quarter of the city (Arias-Sans \& Quaglieri Domínguez, 2016) to the ways we lose something when we forget how to value things without a price tag, a more individualistic, transactional, less creative commons may lead to more manipulation, exploitation, abuse, and conflict. The concept of ethical consumption or responsible tourism where autonomy, community, or participation is valued now seems quaint as values become guided by the logic of the market and demand for travel rendered "frictionless".

The substance and integrity of social life weakens as businesses market interactions, emotions, time, and bodies as depreciating assets, and the very notion of what can be shared, bought and rented becomes transformed. As the walls between intimate lives, social relations, community, and the market become permeable, what was once thought unthinkable to buy or sell has changed. While one's intimate or private life will never be ruled by the absolute logic of market, Airbnb is driving a new kind of flatness or depthlessness (Jameson, 1984), leading to the "reductionism of all beings and all cultural differences to a common commodified form" (Harvey, 2000, p. 83). Airbnb generates the illusory abstract space of "friction-free exchange in which the particularity of the participants' social position is obliterated” (Žižek, 1997, p. 156) by removing all obstacles which sustain the exchange process.

The more you give away via Airbnb (e.g. a spare room, time, food), the more commercially customized your world becomes. As economic activity degrades intimate relationships (Zelizer, 2005), the very source of culture of which tourism feeds is threatened as the need for solidarity, cooperation, and obligation become removed. As information, knowledge, and culture are produced through market rather than social relations, the lines of difference between culture, entertainment, information, and 
consumption become blurred to such an extent, that almost everything viewed or interacted with becomes an act or object of consumption. Market morality encourages tourists to seek the ease of market exchanges for experiences over serendipity, the uniqueness of the locale, a nuanced appreciation of journey and relationships. Airbnb also throws into question whether a future self-interested consumer (many of whom do not currently pay stipulated room-tourist taxes through Airbnb) will pay into any tourist accommodation tax system (e.g. the Balearic Islands accommodation eco-tax, the Dubai tourist tax, the Las Vegas Room tax, the Hamburg culture and tourism tax), which often supports environment preservation, transport, and even education.

\section{Conclusion}

Despite political debate about the role of the Airbnb, their actual contributions to public good, autonomy, and external costs (inequality, discrimination, and social exclusion generated by platform use), Airbnb and similar platforms are here to stay. While the existing hotel sector often hides behind complex trading arrangements (e.g. franchising) and/or reclassifies workers (e.g. cleaners, security guards) as subcontracting to skirt responsibilities and costs; governments, political leaders, unions, and activists play a pivotal role in working against exploitive practices to protectlabour and the environment. While problems from market facing businesses in the accommodation sector were structured in forms amenable to non-profit and local authority intervention, such as zoning, ratings, and quality control systems for sustainable businesses and responsible tourism (e.g. Green Globe), Airbnb has sought either to regulate itself or pass the burdens of service, liability, legal, fiscal, and social responsibilities onto hosts and consumers in the name of public good and the "big society".

Airbnb and therefore its listings, for example, do not coordinate with the UNWTO Task Force to Protect Children in Tourism, promote the "Code of Conduct for the Protection of Children from Sexual Exploitation in Travel and Tourism" (ECPAT), or educate hosts about living wages, local laws, and tax compliance. Its efforts to regulate itself hasled to it becoming a founding member of a private trade body called SEUK, which is partnering with Oxford University in the United Kingdom to develop a "trustmark" for the sharing economy Yet, Airbnb has no incentive to self-regulate or incorporate regulations that limit commercial home sharing (Newcomer, 2016), given the most income comes from listings that break local regulations or property owners that own multiple homes. Studies from London (Coldwell, 2016), Barcelona (Arias-Sans \& Quaglieri Domínguez, 2016), Edinburgh (Salway, 30 2016), New York (Cow \& Slee, 2016; Housing Conservation Coordinators Inc, 2016; Schneiderman, 2014) and San Francisco (Budget \& Legislative Analyst's Office's, 2015) show multi-home listings exist in core tourist areas with a prevalence of long-term occupancy by short-term renters.

While disruption and innovation is important to the accommodation sector, Airbnb is not replacing a wasteful and hierarchical hotel sector. It is adding market-based problems to the sector that will be 35 far more difficult to solve or disrupt. As Airbnb penetrates parts of our lives that were previously out of bounds, for ethical or political reasons, and reduces acts of interaction to a monetary transaction, parties will become more influenced by economic incentives than trust underpinned by shared norms, values, or protections. While surging tourism and innovative technology (e.g. software) means cultural capitalism's intersection with tourism is set to increase, it will mean more privatization of the tourism commons, which Žižek (2009a) would see as a violent act which should be resisted. Imperfect technological and entrepreneurial dynamism coupled with vague rules and regulatory and tax evasion without proper oversight and proper accountability will ensure that Airbnb will continue to have consequences and face legal issues. The organizational ethos of the platform will be increasingly recognized as a symptom of predatory laissez-faire platform capitalism, its extractive practice highlighted via community campaigns (e.g. Barcelona, Dublin, San Francisco) and, therefore, be seen to be in need of greater regulation (Katz, 2015). This regulation needs to be innovative, so as to facilitate the needs of its citizens. Rather than replacing Airbnb control with bureaucratic controls or bans that prevent a pathway for hosts to make listings legal, new systems of governance and control such as "algorithmic regulation" (Quattrone, Proserpio, Quercia, Capra, \& Musolesi, 2016) need to be developed. Other 
options might include sharing host data with authorities, allowing registration only for hosts that are legal accommodation providers, an annual limit for hosts who rent out entire homes, and banning all listings in tourist-saturated neighbourhoods.

By utilizing cultural capitalism to critically look at an accommodation sector, we can identify increasing demand from tourists for innovative and memorable experiences directly linked to the cultural affairs of the community in which they are staying. Airbnb has designed an offering to meet this demand by extracting from private lives and common cultural experiences without investing anything in return (e.g. education, training, careers, or local taxes). Airbnb has planted a "false consciousness" by promoting socio-ideological motifs that masks the deeper, underlying harms of its activities. They have increasingly taken on elements of authoritarianism and are using its users as weapons, which may be used against elected officials, neighbours, and competitors for the purposes of exclusion and enclosure. In this new sharing economy, Airbnb hosts may be pitted against elected officials, neighbours against others neighbours, hosts against guests, landlords against tenants and outsourced workers (e.g. cleaners) against hosts. As they vie against one another, and without alternative accommodation systems such as platform cooperatives, Airbnb will continue to exacerbate market problems rather than seeking to fix them in the short to medium term.

Further research may explore whether the shared resources on Airbnb are really excess capacity from the perspective of hosts, or whether, when fulfilling tourist needs, they create shortages within their immediate social circles (e.g. hosting intermediately rather than seeking higher income, fulltime employment, going to college or being able to take a vacation or seek leisure during downtime). In addition, while Airbnb is delivering progressively more market-sourced income to asset owners, more research is needed to explore whether such income is recycled back locally through taxes, wages, and payment for consumer goods and services and whether such income offsets possible decreases in affordable housing. Finally, the impacts of "short-term strangers" on civic life and the authenticity of neighbourhoods in heavily visited destinations should be explored, as well an examination of the disruption to public policy-making in such destinations.

\section{Disclosure statement}

No potential conflict of interest was reported by the authors.

\section{References}

30 Ahmed, M. (2014, January 28). Brits turn to Airbnb to make ends meet. The Times. Retrieved from http://www.thetimes. co.uk/tto/business/industries/technology/article3988333.ece

Airbnb. (2016, April 19). Airbnb launches new products to inspire people to "Live There". Airbnb. Retrieved from https:// www.airbnb.co.uk/press/news/airbnb-launches-new-products-to-inspire-people-to-live-there

Arias-Sans, A., \& Quaglieri Domínguez, A. (2016). Unravelling Airbnb: The case of Barcelona. In G. Richards \& A. P. Russo (Eds.), Reinventing the local in tourism: Travel communities and peer-produced place experiences (pp. 209-228). London: Channel view.

Botsman, R. (2012, August 20). Welcome to the new reputation economy. Wired Magazine. Retrieved from http://www. wired.co.uk/magazine/archive/2012/09/features/welcome-to-the-new-reputation-economy

Botsman, R. (2015, May 27). Defining the sharing economy: What is collaborative consumption - And what isn't? Fast Company. Retrieved from http://www.fastcoexist.com/3046119/defining-the-sharing-economy-what-is-collaborativeconsumption-and-what-isnt

Botsman, R., \& Rogers, R. (2011). What's mine is yours: How collaborative consumption is changing the way we live. London: Harper Collins Business.

Budget and Legislative Analyst's Office. (2015). Analysis of the impact of short-term rentals on housing - City and county of San Francisco board of supervisors. Retrieved from http://www.sfbos.org/Modules/ShowDocument. aspx?documentid $=52601$

Campos, A. C., do Valle, P. O., Mendes, J., \& Scott, N. (2015). Co-creation of tourist experiences: A literature review. Current Issues in Tourism, 33, 1309-1336. doi:10.1080/13683500.2015.1081158

Chase, R. (2015). Peers Inc.: How people and platforms are inventing the collaborative economy and reinventing capitalism. New York, NY: Public Affairs. 
Cheng, M. (2016). Sharing economy: A review and agenda for future research. International Journal of Hospitality Management, 57, 60-70. doi:10.1016/j.ijhm.2016.06.003

Coldwell, W. (2016, March 18). Airbnb: From homesharing cool to commercial giant. The Guardian. Retrieved from http://www.theguardian.com/travel/2016/mar/18/airbnb-from-homesharing-cool-to-commercial-giant

Cow, M., \& Slee, T. (2016, February 10). How Airbnb's data hid the facts in New York City. Retrieved from http://whimsley. s3.amazonaws.com/wordpress/wp-content/uploads/2016/02/how-airbnbs-data-hid-the-facts-in-new-york-city.pdf

Debord, G. (1998). Comments on the society of the spectacle. London: Verso.

Dredge, D., \& Gyimóthy, S. (2015). The collaborative economy and tourism: Critical perspectives, questionable claims and silenced voices. Tourism Recreation Research, 40, 286-302. doi:

10 Edelman, B., Luca, M., \& Svirsky, D. (2016). American Economic Journal: Applied Economics. doi:10.2139/ssrn.2701902

Fiske, A. P. (1992). The four elementary forms of sociality: Framework for a unified theory of social relations. Psychological Review, 99, 689-723.

Guttentag, D. (2016). Airbnb: Disruptive innovation and the rise of an informal tourism accommodation sector. Current Issues in Tourism, 18, 1192-1217. doi:10.1080/13683500.2013.8271

15 Hamari, J., \& Ukkonen, A. (2013). The sharing economy: Why people participate in collaborative consumption. Helsinki Institute for Information Technology.

Harvey, D. (1989). The condition of postmodernity. Oxford: Basic Blackwell.

Harvey, D. (2000). Spaces of hope. Berkeley: University of California Press.

Hochschild, A. R. (2003). The commercialization of intimate life: Notes from home and work. Berkeley: University of California Press.

Holloway, J. (2010). Crack capitalism. London: Pluto.

Housing Conservation Coordinators Inc. (2016). Short changing New York City: The impact of Airbnb on New York City's housing market. Retrieved from http://www.sharebetter.org/wp-content/uploads/2016/06/NYCHousingReport_Final. pdf

Howard, B. (2015). We-commerce: How to create, collaborate, and succeed in the sharing economy. Perigee Books, Penguin Random House.

Howell, R. T., Pchelin, P., \& Iyer, R. (2012). The preference for experiences over possessions: Measurement and construct validation of the experiential buying tendency scale. The Journal of Positive Psychology, 7, 57-71. doi:10.1080/1743 9760.2011 .626791

30 Ikkala, T., \& Lampinen, A. (2014). Defining the price of hospitality: Networked hospitality exchange via Airbnb. In CSCW Companion ' 14 Proceedings of the companion publication of the 17th ACM conference on Computer supported cooperative work \& social computing, 173-176. doi:10.1145/2556420.2556506

Jameson, F. (1984). Postmodernism, or the cultural logic of late capitalism. New Left Review, 146, 59-92.

Katz, L. F., \& Krueger, A. B. (2016). The rise and nature of alternative work arrangements in the United States, 1995-2015. NBER. Retrieved from http://scholar.harvard.edu/files/lkatz/files/katz_krueger_cws_v3.pdf?m=1459369766

Katz, V. (2015). Regulating the sharing economy. Berkeley Technology Law Journal, 30, 1067-1126.

King, D. (2015). Survey finds surge in peer-to-peer home rentals, ride-hailing. Travel Weekly. Retrieved from http://www. travelweekly.com/Travel-News/Travel-Technology/Survey-finds-surge-in-peer-to-peer-home-rentals-ride-hailing

Krakovsky, M. (2015). The middleman economy. New York, NY: Palgrave Macmillan.

40 Kramer, B. (2015). Shareology: How sharing is powering the human economy. New York, NY: Morgan James Publishing.

Luchs, M. G., Naylor, R. W., Rose, R. L., Catlin, J. R., Gau, R., \& Kapitan, S. (2011). Toward a sustainable marketplace: Expanding options and benefits for consumers. Journal of Research for Consumers, 19, 1-12.

Lynam, J. (2016, February15). Airbnb 'delisting hosts for no reason'. BBC. Retrieved from http://www.bbc.co.uk/news/ business-35574971

Moazed, A., \& Johnson, N. L. (2016). Modern monopolies: What it takes to dominate the 21st century economy. New York, NY: St. Martin's Press.

Phipps, M., Ozanne, L., Luchs, M., Subrahmanyan, S., Kapitan, S., \& Catlin, J. (2013). Understanding the inherent complexity of sustainable consumption: A social cognitive framework. Journal of Business Research, 66, 1227-1234. doi:10.1016/j.jbusres.2012.08.016

50 PwC. (2014). The sharing economy. PriceWaterhouseCoopers. Retrieved from http://download.pwc.com/ie/pubs/2015pwc-cis-sharing-economy.pdf

Quattrone, G., Proserpio, D., Quercia, D., Capra, L., \& Musolesi, M. (2016, April 11-15). Who benefits from the "sharing" economy of Airbnb? Proceedings of the 25th International Conference on World Wide Web, Montréal, Québec, Canada. doi:10.1145/2872427.287481

55 Quinby, D. (2016). The end of alternative accommodation: Airbnb is now the third-largest online accommodation seller worldwide. Phocuswright. Retrieved from http://www.phocuswright.com/Travel-Research/Research-Updates/2016/ The-End-of-Alternative-Accommodation

Rifkin, J. (2000). The age of access: The new culture of hypercapitalism, where all of life is a paid-for experience. New York, NY: J.P. Tarcher/Putnam.

60 Salway, J. (2016, August 6). Rise of Airbnb 'makes housing crisis worse'. The Scotsman. Retrieved from http://www. scotsman.com/business/companies/jeff-salway-rise-of-airbnb-makes-housing-crisis-worse-1-4196111 
Schneiderman, E. T. (2014). Airbnb in the city. New York State Attorney General. Retrieved from http://www.ag.ny.gov/ pdfs/Airbnb\%20report.pdf

Sevignani, S. (2013). The commodification of privacy on the Internet. Science and Public Policy, 40, 733-739. doi:10.1093/ scipol/sct082

Smith, A. (2016, May 19). Shared, collaborative and on demand: the new digital economy. Pew Research Center. Retrieved from http://www.pewinternet.org/2016/05/19/the-new-digital-economy/

Sperling, G. (2015). How Airbnb combats middle class income stagnation. Airbnb. Retrieved from https://airbnb.box. com/shared/static/jrry0if4cgirnvwlykrpmw8ugivrx2mx.pdf

Stephany, A. (2015). The business of sharing. London: Palgrave Macmillan.

Tussyadiah, I. P., \& Pesonen, J. (2016). Drivers and barriers of peer-to-peer accommodation stay - An exploratory study with American and Finnish travellers. Current Issues in Tourism. doi:10.1080/13683500.2016.1141180.

Ullrich, W. (2012). Habenwollen. Wie funktioniert die konsumkultur?. Frankfurt/Main: Fischer.

Wang, D., Xi, S., \& Gilheany, J. (2015). The model minority? Not on airbnb.com: A hedonic pricing model to quantify racial bias against Asian Americans. Technology Science. Retrieved from http://techscience.org/downloadpdf. php?paper $=2015090104$

Zelizer, V. A. (2005). The purchase of intimacy. Princeton, NJ: Princeton University.

Zervas, G., Proserpio, D., \& Byers, J. W. (2015). A first look at online reputation on Airbnb: Where every stay is above average. (Working paper). Retrieved from http://collaborativeeconomy.com/wp/wp-content/uploads/2015/04/ Byers-D.-Proserpio-D.-Zervas-G.2015.A-First-Look-at-Online-Reputation-on-Airbnb-Where-Every-Stay-is-AboveAverage.Boston-University.pdf

Žižek, S. (1997). The plague of fantasies. London: Verso.

Žižek, S. (2006). The universal exception. London: Continuum.

Žižek, S. (2009a). First as tragedy, then as farce. London: Verso.

Žižek, S. (2009b, November 24). RSA animate: First as tragedy, then as farce. RSA. Retrieved from https://www.thersa. org/globalassets/pdfs/blogs/rsa-lecture-slovoj-zizek-transcript.pdf

Žižek, S. (2011). Living in the end times. London: Verso.

Žižek, S. (2012). Organs without bodies: On deleuze and consequences. London: Routledge.

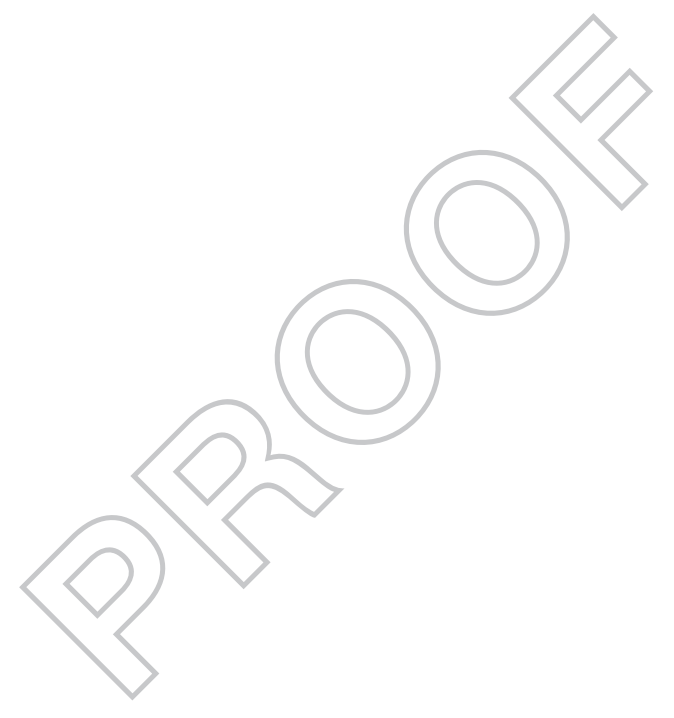

